\title{
A QUESTÃO DA LIBERDADE PRÁTICA NA CRÍTICA DA RAZÃO PURA
}

The Question of Practical Freedom in the Critique of Pure Reason

Antonio Saturnino Braga *

Resumo: Este artigo tem três objetivos inter-relacionados. Em primeiro lugar, defender uma interpretação compatibilista da noção de liberdade prática exposta no capítulo do Cânone da Crítica da Razão Pura. Em segundo lugar, defender a hipótese de que a noção incompatibilista de liberdade prática exposta no capítulo das Antinomias da mesma Crítica incorre em sérios problemas. Por fim, defenderemos uma hipótese mais abrangente: se por um lado, para evitar os problemas suscitados pela interpretação incompatibilista, a liberdade prática deve ser interpretada num sentido compatibilista, para ser interpretada deste modo ela precisa por outro lado ser compreendida como propriedade da atividade deliberativa da razão prática, essencialmente distinta da atividade legislativa, à qual cabe a noção incompatibilista da liberdade transcendental.

Palavras-chave: Kant. Crítica da Razão Pura. Liberdade Prática. Compatibilismo e Incompatibilismo. Deliberação e Legislação.

Abstract: This paper has three interrelated aims. The first defends a compatibilist interpretation of the concept of practical freedom presented in the Canon chapter of the Critique of Pure Reason. The second defends the hypothesis that the incompatibilist concept of practical freedom, presented in the Antinomies chapter of the same Critique, involves serious problems. Finally, the third defends a more comprehensive hypothesis: If, to avoid the serious problems created by

* Doutor em Filosofia pela Universidade do Estado do Rio de Janeiro (2007). Professor do Instituto de Filodofia e Ciências Sociais, Departamento de Filosofia da Universidade Federal do Rio de Janeiro. Artigo recebido em 18/02/15 e aprovado para publicação em 01/09/2015. 
the incompatibilist interpretation, practical freedom must be interpreted in a compatibilist way, on the other hand, to be interpreted in this way, practical freedom must be understood as a property of the deliberative activity of practical reason. The latter being essentially distinct from legislative activity, to which the incompatibilist concept of transcendental freedom applies.

Keywords: Kant. Critique of Pure Reason. Practical Freedom. Compatibilism and Incompatibilism. Deliberation and Legislation.

$\mathrm{E}$ ste artigo tem três objetivos. Em primeiro lugar, defender uma certa interpretação compatibilista da noção de liberdade prática exposta no capítulo do Cânone da Razão Pura da Crítica da Razão Pura. De acordo com a interpretação compatibilista que será defendida aqui, a espontaneidade envolvida na liberdade prática é uma espontaneidade relativa e limitada, compatível com a influência causal em última instância determinante de fatores causais atuantes no tempo - os quais, para serem compatíveis com a experiência da espontaneidade prática, devem ser entendidos como fatores de cuja atuação o sujeito não tem inteira consciência ou clareza. Esta interpretação se opõe à interpretação incompatibilista, segundo a qual a espontaneidade envolvida na liberdade prática tem de ser tomada como espontaneidade absoluta, um Poder de agir a partir apenas de si mesmo, independentemente de qualquer influência causal de fatores previamente dados no tempo. O segundo objetivo de nosso artigo é defender a hipótese de que a noção incompatibilista de liberdade prática exposta no capítulo da Antinomia da Razão Pura da mesma Crítica incorre em problemas sérios, que evidenciam a superioridade da noção compatibilista exposta no Cânone. Por fim, o terceiro objetivo é propor um quadro interpretativo mais geral para a filosofia prática kantiana, baseado na seguinte hipótese: se por um lado, para evitar os problemas suscitados pela interpretação incompatibilista, a liberdade prática deve ser interpretada num sentido compatibilista, para poder ser interpretada deste modo ela precisa por outro lado ser compreendida como propriedade da atividade deliberativa da razão prática, uma atividade essencialmente distinta da atividade estritamente legislativa, à qual cabe a noção incompatibilista da liberdade transcendental, equivalente ao conceito de uma espontaneidade absoluta.

Cabe destacar que o terceiro objetivo, o mais abrangente, é o princípio que sustenta meu argumento como um todo. $\mathrm{O}$ propósito da discriminação dos dois primeiros objetivos é apenas enfatizar que o quadro interpretativo mais geral foi aqui elaborado com base apenas na leitura e discussão das análises sobre a liberdade efetuadas na Crítica da Razão Pura. Como o quadro interpretativo tem um alcance mais geral, referências a outras obras de Kant se tornam aqui e ali inevitáveis, mas o objetivo do artigo é elaborar o quadro geral a partir apenas da Crítica da Razão Pura, deixando 
para artigos futuros o trabalho de "testar" o quadro interpretativo a partir do cotejo com outras obras da filosofia prática kantiana.

$\mathrm{O}$ artigo se divide em quatro partes. Na primeira, introduzo as hipóteses fundamentais do quadro geral a partir de uma exposição e análise das passagens essenciais dos capítulos da Antinomia e do Cânone. Na segunda, elaboro de modo mais preciso tais hipóteses através de um confronto com a interpretação exposta por Henry Allison em seu livro Kant's Theory of Freedom (1990). Na terceira, apresento os graves problemas suscitados pela interpretação incompatibilista da liberdade prática, defendida não apenas por Allison mas também por Allen Wood em seu artigo Kant's Compatibilism (1984) - o "compatibilismo" do título de Wood não se refere a uma interpretação compatibilista da liberdade prática, mas, sim, à compatibilidade do conceito incompatibilista de liberdade prática com o conceito rigorosamente determinista da causalidade da natureza. $\mathrm{Na}$ quarta parte, por fim, procuro apresentar de forma sucinta de que modo a interpretação compatibilista da liberdade prática permitiria superar os graves problemas suscitados pela interpretação incompatibilista.

Na Crítica da Razão Pura, Kant desenvolve a questão da liberdade através da discussão de duas ideias: liberdade prática e liberdade transcendental. As definições dessas duas ideias, a relação entre elas e seu impacto na teoria da liberdade em geral são apresentados em duas grandes passagens, a primeira situada no capítulo das antinomias da razão pura e a segunda no capítulo do cânone da razão pura. Numa primeira leitura, estas duas passagens exibem uma característica surpreendente. Embora as definições das duas ideias de liberdade pareçam ser idênticas, a relação entre elas é apresentada de modo radicalmente divergente nas duas passagens. No capítulo das antinomias, Kant afirma que "o conceito prático da liberdade se funda sobre a ideia transcendental" (B561/A533) e que "a supressão da liberdade transcendental aniquilaria, concomitantemente, toda a liberdade prática" (B562/A534); não pode haver expressão mais clara da dependência da liberdade prática em relação à transcendental. Já no capítulo do cânone Kant afirma que "conhecemos por experiência a liberdade prática, como uma das causas naturais, (...) enquanto a liberdade transcendental (...) parece ser contrária à lei da natureza e, portanto, a toda a experiência possível, permanecendo, pois, um problema" (B831/A803); afirmação que claramente implica a independência da liberdade prática em relação à transcendental.

Analisemos de forma mais detida as definições das duas ideias de liberdade, começando pelo capítulo das antinomias. Neste capítulo, a ideia da 
liberdade transcendental equivale à ideia cosmológica de uma causalidade temporalmente incondicionada, ou seja, de um poder causal cuja atividade não é por sua vez condicionada por fatores causais previamente dados no tempo, ao contrário do que ocorre com as causas da natureza. Nas palavras de Kant, "Entendo por liberdade, no sentido cosmológico, a faculdade de iniciar por si (von selbst) um estado, cuja causalidade, pois, não está por sua vez, segundo a lei da natureza, sob uma outra causa que a determine quanto ao tempo" (B561/A533). A liberdade prática seria então a expressão desta faculdade no âmbito do arbítrio humano, tomado como faculdade de produzir ações (eventos) no espaço e tempo. Com efeito, embora seja afetado por impulsos (Antriebe) e motivações (Bewegursachen) da sensibilidade, o arbítrio humano, ao contrário do arbítrio "animal", não é nem pode ser simplesmente necessitado (ou coagido) por tais impulsos e motivações, caracterizando-se, ao contrário, pela capacidade de determinar-se "por si mesmo (von selbst)" (B562/A534). No capítulo das antinomias, ao afirmar que a liberdade prática depende essencialmente da transcendental, Kant parece estar querendo dizer que esta capacidade do arbítrio humano de determinar-se "por si mesmo" implica absoluta independência em relação a qualquer influência causal de fatores motivacionais previamente dados no tempo, ou seja, implica uma espontaneidade absoluta.

No capítulo das antinomias, em outras palavras, a única alternativa à "necessitação" por impulsos da sensibilidade é a absoluta independência em relação a qualquer forma de determinação por fatores causais previamente dados no tempo. Neste contexto, a liberdade do arbítrio humano pressupõe que se possa encarar cada ação do arbítrio como "totalmente incondicionada em relação ao estado anterior, como se o autor com ela iniciasse, de todo espontaneamente (ganz von selbst), uma série de conseqüências" (B583/A555). Antecipando uma análise que será elaborada mais à frente, pode-se dizer que nas Antinomias não se admite a possibilidade de que a liberdade equivalha a uma forma de causalidade que, mesmo não sendo imediatamente determinada por impulsos da sensibilidade, por envolver uma atividade racional de ponderação e ajuizamento de tais impulsos, no seio da qual tais impulsos só têm papel causal à medida que são transformados em "razões para agir", isto é, representações conscientes e neste sentido racionais sobre o que é bom na vida humana, - não se admite aqui a possibilidade de que a causalidade do livre-arbítrio seja em última instância determinada por fatores causais de cuja atuação o agente não tem inteira consciência ou clareza e sobre os quais não tem inteiro controle.

Passemos agora ao capítulo do cânone. Neste capítulo, a exposição da liberdade transcendental é secundária em relação à da liberdade prática e é feita apenas através do contraste com esta última. De um modo geral, em nome de um foco exclusivo no uso prático da razão, o Cânone se caracteriza por uma dispensa da questão especulativa sobre o estatuto ontológico da liberdade, no quadro da qual apenas se tornaria impres- 
cindível um posicionamento mais preciso quanto à idéia da liberdade transcendental. Pode-se destacar ainda outra característica deste capítulo. $\mathrm{Na}$ definição da liberdade prática nele apresentada, a independência em relação à coerção ou necessitação por impulsos da sensibilidade é associada, não tanto à capacidade do arbítrio de determinar-se "por si mesmo", mas, antes, à capacidade do arbítrio de ser determinado "por motivações (Bewegursachen) que são representadas apenas pela razão", que são "representações daquilo que, mesmo de um modo mais remoto, é útil ou prejudicial" (B830/A802), ou seja, representações sobre o bem e o mal em geral. Percebe-se aqui, portanto, uma ligeira diferença na caracterização "positiva" da liberdade prática: enquanto nas Antinomias tal marca positiva é descrita como a capacidade do arbítrio de determinar-se "por si mesmo", no Cânone ela é descrita como a capacidade do arbítrio de ser determinado por representações da razão acerca do bem e mal em geral. Discutiremos daqui a pouco se esta diferença terminológica corresponde ou não a alguma diferença conceitual importante.

Quanto à liberdade transcendental, também no Cânone a marca da causalidade incondicionada é inequivocamente apresentada como característica essencial desta espécie de liberdade. Com efeito, enquanto a liberdade prática consiste em uma "causalidade da razão na determinação da vontade (des Willens)", a liberdade transcendental "exige uma independência desta mesma razão (com referência à sua causalidade ao começar uma série de fenômenos) diante de todas as causas determinantes do mundo sensível" (B831/A803).

Esta passagem exibe um aspecto importante de toda a discussão sobre a liberdade prática e sobre a relação da liberdade prática com a transcendental, um aspecto, aliás, que é decisivo também no capítulo das antinomias. Embora a liberdade prática (e a transcendental, na medida em que é analisada em sua relação com a prática) constitua uma propriedade do Poder causal do homem como sujeito racional, há certa ambiguidade quanto à faculdade humana à qual esta propriedade deva mais exatamente ser atribuída. Em princípio ela deve ser atribuída àquela faculdade que mais imediatamente exerce o papel de causa, a saber, à vontade como faculdade de produzir ações (um tipo de evento) no espaço e no tempo, isto é, ações que aparecem aos observadores em geral - aliás, cabe destacar que, tomada como faculdade de produzir ações no espaço e tempo, a vontade é idêntica ao "arbítrio" (Willkür). Mas o arbítrio humano é livre à medida que é racional, ou seja, à medida que é determinado a agir (e com isso causar ações como eventos que aparecem aos observadores), não por meros impulsos da sensibilidade, mas por ideias ou representações da razão, que como vimos são ideias sobre o bem e o mal em geral. Parece plausível compreender esta determinação do arbítrio por ideias da razão como determinação do mesmo por uma atividade judicativa pela qual a razão define qual representação será determinante na ação do arbítrio. Podemos chamar esta atividade judicativa de atividade "deliberativa" da 
razão prática, que será importante distinguir de uma atividade estritamente legislativa. Voltaremos a este ponto logo a seguir. De qualquer modo, é a determinação do arbítrio por esta atividade "deliberativa" que permite a Kant falar de uma "causalidade da razão", que equivale justamente ao Poder da razão de, através das ideias por ela formuladas, ajuizadas e erigidas em regras de conduta, "causar" esta ou aquela ação do arbítrio.

Assim, a causalidade da razão refere-se ao Poder causal da atividade deliberativa pela qual a razão não apenas formula diferentes espécies de razões para agir, como pondera tais razões e de algum define qual dentre elas será determinante na atividade do arbítrio, erigindo-a em regra de conduta para o arbítrio. Pode-se então afirmar que a liberdade humana apresenta pelo menos duas facetas: em primeiro lugar, ela pode ser apresentada como uma capacidade do arbítrio humano, capacidade de determinar-se à ação, não por meros impulsos sensíveis, mas por representações conscientes e racionais; em segundo lugar, a liberdade pode ser apresentada como uma capacidade da razão humana, capacidade de definir qual representação sobre o bem (e mal) será determinante para a atividade pela qual o arbítrio produz ações observáveis.

Mais à frente teremos de discutir se não seria necessário incluir uma terceira faceta, dizendo respeito a uma outra capacidade da razão humana, distinta da capacidade de ponderar representações sobre o bem e definir qual dentre elas será determinante para a ação do arbítrio: trata-se da capacidade de reconhecer verdades sobre o modo racional de agir e "pôr" tais verdades como normas que devem ser seguidas pelo arbítrio humano, normas que são válidas mesmo que não sejam de fato seguidas pelo arbítrio dos sujeitos em geral. No quadro terminológico kantiano, esta última capacidade naturalmente recebe o nome de capacidade "legislativa" da razão prática, no contraste com a qual a capacidade de ajuizar e definir qual representação sobre o bem será de fato seguida pelo arbítrio pode ser chamada de capacidade "deliberativa", mesmo que o termo não seja tão característico do vocabulário kantiano.

De qualquer modo, como sugerido acima, a expressão "causalidade da razão na determinação da vontade (ou arbítrio)" certamente não se refere a esta capacidade legislativa da razão prática, mas só pode se referir à capacidade deliberativa. Com efeito, a "causalidade da razão" só pode se referir à capacidade de definir qual representação terá papel causal determinante nas ações do arbítrio, ou seja, qual representação será de fato seguida pelas ações do arbítrio; na medida em que as normas prescritas pela capacidade legislativa são válidas mesmo que não sejam seguidas pelas ações do arbítrio, ou seja, mesmo que não exerçam nenhum papel causal nas ações que o arbítrio de fato realiza (como ocorre na maior parte das vezes), a "causalidade da razão na determinação do arbítrio" não pode se referir à capacidade legislativa da razão prática. 
A passagem do Cânone acima citada deixa claro que a compreensão tanto da liberdade prática quanto da relação da prática com a transcendental passa necessariamente pela compreensão desta capacidade deliberativa da razão prática, ou pela compreensão desta "causalidade da razão na determinação da vontade". Ainda que a compreensão da atividade legislativa venha a exigir o conceito de liberdade transcendental e venha a recorrer a ele, este conceito certamente comparecerá também na discussão da atividade deliberativa, na medida em que é esta atividade que exerce papel causal na produção das ações no espaço e tempo. Em outras palavras, ainda que o conceito de liberdade transcendental deva ser referido a uma propriedade da atividade legislativa da razão prática, ele certamente exprimirá também uma certa compreensão da atividade deliberativa. Mais precisamente, ele exprime uma compreensão incompatibilista da atividade deliberativa, segundo a qual tal atividade é absolutamente independente de qualquer influência causal de fatores motivacionais pertencentes à natureza do agente. De acordo com esta compreensão, há uma incompatibilidade essencial entre a espontaneidade da atividade deliberativa e a influência causal de fatores motivacionais que foram simplesmente dados ao agente. Ao afirmar que a liberdade prática é essencialmente dependente da transcendental, ao sugerir que a liberdade prática é simplesmente um caso da liberdade transcendental, o capítulo das antinomias está endossando esta concepção incompatibilista da atividade deliberativa da razão prática. Em contrapartida, ao afirmar a independência da liberdade prática em relação à transcendental, o Cânone estaria defendendo uma concepção compatibilista da atividade deliberativa, segundo a qual a espontaneidade da atividade deliberativa é compatível com a influência causal de fatores motivacionais constitutivos da natureza do sujeito racional. (Mais à frente, na seção II, discutiremos se seria justificável realizar um "recorte seletivo" na passagem do Cânone em que Kant sugere uma interpretação compatibilista inclusive da atividade legislativa).

Tentemos elaborar um pouco mais esta linha de análise. No capítulo do cânone, a distinção entre as duas formas de liberdade e a independência da prática em relação à transcendental parecem remeter à seguinte compreensão da atividade deliberativa. No âmbito do conceito "problemático" de liberdade transcendental, a atividade pela qual a razão decide qual ideia ou regra (sobre o bem) será determinante para as ações do arbítrio é pensada como totalmente independente de qualquer "causa determinante do mundo sensível", ou seja, de qualquer fator causal previamente dado no tempo. Isto significa que, ao definir qual representação sobre o bem será determinante para a ação do arbítrio, a razão não seria condicionada ou influenciada por qualquer fator causal previamente dado, incluindo fatores dos quais o sujeito possivelmente não tivesse perfeita consciência - na verdade, o próprio conceito da liberdade transcendental exclui a possibilidade de que fatores de que o sujeito não tenha consciência e 
controle venham a influir sobre a "causalidade da razão", isto é, sobre a atividade deliberativa pela qual a razão define qual ideia ou regra sobre o bem será determinante para o arbítrio.

Já no caso da liberdade prática tal como exposta no capítulo do cânone, ao afirmar que nós "a conhecemos por experiência como sendo uma das causas naturais" (B831/A803), Kant parece autorizar a interpretação de que, nesta espécie de liberdade, a atividade deliberativa é concebida como compatível com a influência em última instância determinante de fatores causais previamente dados no tempo. É claro que, para serem compatíveis com a experiência da espontaneidade da atividade deliberativa, tais fatores causais em última instância determinantes têm de ser fatores de cuja atuação o sujeito não tem inteira consciência ou clareza. A espontaneidade da atividade deliberativa seria, portanto, uma espontaneidade limitada e relativa, que certamente se sustenta ao ser comparada com a necessitação por impulsos sensíveis própria de um arbítrio "animal", mas é por outro lado compatível com a determinação por influências causais "mais elevadas e remotas" (B831/A803), que seriam fatores de cuja atuação causal o sujeito não tem inteira consciência. Isso explica a impactante afirmação de Kant no Cânone de que a liberdade prática, enquanto capacidade cuja realidade "pode ser demonstrada por experiência" (B830/A802), não seria afetada pela possibilidade de que "isto que se chama liberdade com respeito aos impulsos sensíveis seja por sua vez natureza com respeito a causas eficientes mais elevadas e remotas" (B831/A803). (Como dito acima, mais à frente, na seção II, discutiremos se seria justificável realizar um "recorte seletivo" na frase imediatamente anterior a esta, que sugere uma interpretação compatibilista inclusive da atividade legislativa).

Em outras palavras, ao sustentar a independência da liberdade prática em relação à transcendental, o Cânone parece defender uma concepção compatibilista da liberdade prática, que pode ser apresentada nos seguintes termos. Se é por um lado verdade que tal espécie de liberdade consiste na capacidade do arbítrio humano de ser determinado à produção desta ou daquela ação independentemente da coerção ou necessitação por impulsos sensíveis, isto é, ser determinado à ação a partir de motivos constituídos por representações racionais sobre o que é bom ou mau a longo prazo, a espontaneidade envolvida na formulação, avaliação e adoção dessas representações racionais pode perfeitamente ser uma espontaneidade limitada, compatível com a determinação por influências causais "mais elevadas e remotas".

Em contrapartida, ao afirmar a dependência da liberdade prática em relação à transcendental, o capítulo das antinomias parece defender uma concepção incompatibilista da liberdade prática, segundo a qual a atividade essencial da liberdade humana, que é a atividade deliberativa pela qual a razão define qual regra sobre o bem será seguida pelo arbítrio, é 
totalmente incompatível com uma possível determinação da mesma por fatores causais de que o sujeito não tivesse inteira clareza ou consciência. Ao definir qual idéia sobre o bem será determinante para o arbítrio, a razão exerceria um Poder causal totalmente independente em relação a qualquer tipo de fator causal previamente dado no tempo, ou seja, um Poder causal que atua apenas a partir de si mesmo, ou "por si mesmo".

Vemos agora que a diferença acima apontada na caracterização "positiva" da liberdade prática de fato corresponde a uma diferença conceitual importante. Se no capítulo das antinomias a marca positiva da liberdade prática é apresentada em termos de capacidade do arbítrio de determinar-se "por si mesmo", isto reflete uma concepção incompatibilista da "causalidade da razão na determinação do arbítrio". O arbítrio racional determina-se por si mesmo porque a atividade racional que define qual regra lhe será determinante é ela própria independente e incondicionada em relação a qualquer fator causal previamente dado no tempo. Por outro lado, se no capítulo do cânone a fórmula da "determinação por si mesmo" é deixada de lado e substituída pela caracterização em termos de "determinação por representações da razão", isto reflete a concepção compatibilista da causalidade da razão, no contexto da qual as representações da razão, enquanto representações determinantes do arbítrio, não são elas próprias expressão de uma capacidade deliberativa que atua a partir apenas de si mesma, ou por si mesma.

Em seu livro Kant's Theory of Freedom, Henry Allison rejeita uma interpretação compatibilista da liberdade prática no Cânone, tal como a que estivemos propondo até aqui. Para Allison, tal interpretação é inconciliável com a noção de "causalidade da razão" na determinação do arbítrio. Para ele, em outras palavras, "se a liberdade prática é compreendida como envolvendo uma genuína causalidade da razão, ela tem de ser interpretada num sentido incompatibilista" (ALLISON 1990, p.64) - embora, por outro lado, ele admita a independência desta liberdade prática incompatibilista em relação a um conceito incompatibilista mais forte, expresso na idéia de liberdade transcendental. Para o autor, a grande questão do Cânone é entender como é possível haver uma genuína causalidade da razão (que exige uma interpretação incompatibilista da liberdade) que "fique aquém da liberdade transcendental plena", isto é, como é possível haver "uma causalidade da razão na qual esta razão não seja independente 'de todas as causas determinantes no mundo sensível'” (IDEM, p.64-65). Para Allison, isto só seria possível se a dependência da razão em relação a estas causas determinantes não fosse exatamente uma dependência causal. 
Segundo o autor, esta noção de uma dependência não-causal pode ser esclarecida pela admissão de que a vontade humana possa exigir "algum estímulo sensível para desencadear sua ação". Neste caso "nossa natureza sensível constituiria uma condição restritiva de nossa ação, mas não um determinante causal da mesma, na medida em que não nos necessitaria a agir de nenhum modo particular" (ALLISON 1990, p.65). Em outras palavras, "a característica distintiva da liberdade prática é que ela envolve independência da determinação por qualquer desejo ou inclinação particular, mas não (necessariamente) independência da determinação pelo desejo ou inclinação em geral" (IDEM, p.65). Para Allison, o capítulo do cânone apresenta claramente a possibilidade de que a liberdade num sentido incompatibilista seja atribuída a uma vontade que não é capaz de agir "por dever", ou a partir do puro respeito pela Lei, uma vontade, portanto, que será classificada como "heterônoma" pela teoria moral que Kant amadurece depois da primeira edição da Crítica da Razão Pura.

A interpretação incompatibilista que Allison defende para a liberdade prática no Cânone está claramente ligada àquilo que ele chama de "tese da incorporação", que para ele é um elemento essencial da teoria da ação racional adotada por Kant e, por conseguinte, de todos os conceitos de liberdade atribuíveis ao filósofo alemão, e não, apenas, daqueles conceitos mais intimamente associados à teoria moral amadurecida depois de 1781, que têm um caráter incompatibilista mais acentuado. De acordo com a tese da incorporação, o agir racional necessariamente pressupõe "um ato de espontaneidade da parte do agente, através do qual uma inclinação ou desejo é considerado ou tomado como uma base apropriada da ação" (ALLISON 1990, p.39). Este "tomar algo como uma base apropriada para a ação" seria o análogo prático da espontaneidade do entendimento e da razão em suas funções epistêmicas, realizadas na atividade do juízo. Assim, "mesmo uma ação baseada em algum desejo, ou, como Kant a chamará depois, a ação 'heterônoma', envolve a autodeterminação do sujeito e, portanto, um 'momento' de espontaneidade" (IDEM, p.39) - e para Allison esta espontaneidade tem de ser compreendida em termos incompatibilistas, como espontaneidade absoluta, definida pela completa independência em relação a qualquer forma de determinação por fatores causais previamente dados no tempo.

De acordo com Allison, portanto, a diferença entre uma vontade heterônoma e uma vontade autônoma não reside no fato de a primeira ser dotada de uma liberdade meramente compatibilista e a segunda de uma liberdade incompatibilista; para nosso comentador, as duas espécies de vontade se definem por uma liberdade incompatibilista, isto é, pela capacidade de, de modo absolutamente espontâneo e independente de qualquer forma de determinação por motivações previamente dadas no tempo, tomar 
("incorporar") algo como uma base apropriada para a ação. A diferença entre elas consiste no fato de que, no caso da vontade heterônoma, este "algo" precisa necessariamente ser algum desejo dado na sensibilidade, enquanto na vontade autônoma este algo consiste sempre na Lei Moral (como lei posta pela razão pura prática) e no sentimento de respeito produzido apenas pela consciência desta Lei.

Para Allison, como já foi dito, o capítulo do cânone claramente expõe a possibilidade de que a liberdade num sentido incompatibilista seja atribuída a uma vontade heterônoma, ou seja, uma vontade que precisa de algum estímulo ou desejo sensível para determinar-se à ação, embora não seja determinada a esta ou àquela ação por nenhum desejo em particular, determinando-se, ao contrário, por um ato deliberativo que espontaneamente toma este ou aquele desejo como uma base apropriada para a ação, escolhe este ou aquele desejo como uma base adequada da ação. E, por ser dotada da liberdade num sentido incompatibilista, tal vontade, ainda que heterônoma, tem o poder de espontaneamente adotar um certo desejo particular como base adequada para a ação, a saber, o desejo de ser recompensada por seu merecimento de ser feliz. A ideia de Allison, portanto, é que, ainda que precise de algum desejo para mover-se à produção desta ou daquela ação, a vontade heterônoma tem a capacidade de espontaneamente escolher qual desejo ela adotará como base apropriada de suas ações - e isto num sentido absoluto, isto é, no sentido de que tal vontade tem perfeito controle sobre este ato de escolher qual desejo será "incorporado" como base apropriada das ações produzidas no espaço e tempo. E esta vontade heterônoma será moralmente boa quando escolher e adotar os desejos de merecer a felicidade e de ser recompensada por este merecimento como bases apropriadas de sua ação. Se a leitura de Allison por mim apresentada até aqui estiver correta, a independência da liberdade prática em relação à transcendental defendida no Cânone seria uma expressão do fato de que uma vontade heterônoma pelos critérios posteriores (mas dotada de liberdade num sentido incompatibilista) seria suficiente para a moralidade na teoria moral desenvolvida no Cânone - que Allison toma como representativa da posição predominante nas reflexões morais de Kant por volta de 1781 (ALLISON 1990, p.66-70).

Como dito acima, a interpretação incompatibilista que Allison defende para a liberdade prática no Cânone está claramente associada à sua ênfase na "tese da incorporação" como elemento essencial da teoria do agir racional de Kant, um elemento que para ele está presente também no Cânone. Mais precisamente, a interpretação de Allison está associada à compreensão da espontaneidade prática que ele vincula à tese da incorporação. A certeza de Allison de que tal espontaneidade precisa ser compreendida em termos absolutos e incompatibilistas parece estar vinculada à sua ideia de que a 
espontaneidade envolvida na "incorporação" de qualquer desejo sensível é o "análogo prático" da espontaneidade do entendimento e da razão em suas funções epistêmicas (Cf. ALISSON 1990, p.36-40). Allison não parece atentar para a possibilidade de que a espontaneidade da atividade deliberativa seja essencialmente distinta não apenas da espontaneidade estritamente epistêmica da razão teórica, mas também da espontaneidade especificamente legislativa da razão prática, na qual o componente epistêmico desempenha um papel muito mais robusto do que na atividade deliberativa, como se verá logo a seguir.

De acordo com a interpretação de Allison, a espontaneidade do sujeito que delibera racionalmente "pode ser provisoriamente [a citação é da Introdução - A.S.B.] caracterizada como a capacidade de determinar-se a agir com base em normas racionais objetivas (intersubjetivamente válidas) e de, à luz dessas normas, tomar (ou rejeitar) inclinações ou desejos como razões suficientes para a ação" (ALLISON 1990, p.5). Como sugerido acima, o aspecto decisivo desta compreensão é que ela implicitamente aproxima e até identifica a espontaneidade implicada no ato de "tomar (ou rejeitar) inclinações ou desejos como razões suficientes para a ação" com, por outro lado, a espontaneidade implicada na atividade de formular e impor "normas racionais e objetivas", isto é, normas racionais sobre como se deve agir, os "imperativos". Ora, como esta última espontaneidade, especialmente quando considerada em relação à formulação e imposição do imperativo categórico, de fato parece ser inconciliável com qualquer interpretação de tipo compatibilista, a identificação da mesma com a espontaneidade da atividade estritamente deliberativa (apresentada na passagem acima como atividade de tomar inclinações ou desejos como razões suficientes para a ação) acaba levando à necessidade de também se conferir uma interpretação incompatibilista a esta espontaneidade da atividade deliberativa.

O próprio texto do Cânone sugere a identificação implicitamente efetuada por Allison, só que com um resultado em certo sentido oposto, e tão surpreendente que soa inacreditável, a saber, a sugestão de que também a espontaneidade da atividade legislativa admitiria a interpretação compatibilista que poderia parecer mais adequada à atividade deliberativa. Com efeito, na passagem em B830/A802 em que apresenta a distinção entre um arbítrio animal e um arbítrio livre, Kant sugere uma identificação entre, por um lado, o Poder de determinar-se à ação independentemente da necessitação por impulsos sensíveis e a partir de representações racionais sobre o bem e mal em geral, que no esquema que estamos propondo corresponde à espontaneidade da atividade deliberativa, e, por outro lado, a capacidade de fornecer imperativos, ou leis objetivas das ações livres, que dizem como essas ações devem acontecer, mesmo que frequentemente não aconteçam deste modo - capacidade esta que corresponde à espontanei- 
dade propriamente legislativa da razão prática. E logo em seguida, em B831/A803, ele incrivelmente afirma que "Saber se a própria razão, mesmo naquelas ações mediante as quais prescreve leis, não é por sua vez determinada por outras influências, e se isto que, com respeito aos impulsos sensíveis, se chama liberdade, não poderia ser, em relação a causas eficientes mais elevadas e remotas, por sua vez natureza, - saber isto não nos interessa no campo prático (...) (onde) nosso propósito se dirige para o fazer ou o deixar de fazer". Ora, embora se possa discutir a extensão exata da expressão "ações mediante as quais a razão prescreve leis", ela certamente abrange a atividade de formular e prescrever imperativos. E é inegável que, no enquadramento "apriorista" e transcendental da filosofia kantiana, essencialmente contrário à perspectiva naturalista da filosofia humeana, esta última atividade é inconciliável com qualquer tipo de interpretação compatibilista.

A passagem que acabamos de citar apresenta, portanto, nítida incongruência com um princípio fundamental da filosofia kantiana. Para lidar com esta incongruência, parece ser fecundo estabelecer uma distinção entre as duas espécies de espontaneidade acima mencionadas, a legislativa e a deliberativa. Isto permitiria fazer um recorte seletivo na passagem citada, deixando de lado a sugestão de uma interpretação compatibilista da atividade legislativa (e defendendo o caráter incompatibilista da espontaneidade envolvida nesta atividade) e, simultaneamente, admitindo uma compreensão compatibilista da espontaneidade envolvida na atividade deliberativa. No âmbito da espontaneidade legislativa, a atividade da razão desenvolve-se inteiramente a partir de si mesma e "por si mesma", e é incompatível com a determinação por fatores causais pertencentes à mera natureza do sujeito. Neste âmbito, por conseguinte, a atividade da razão possui a propriedade da liberdade transcendental, embora por outro lado não possua Poder causal, não exerça papel causal na determinação do arbítrio. No âmbito da espontaneidade deliberativa, por outro lado, a atividade da razão é compatível com a determinação por fatores causais pertencentes à natureza ou formação do sujeito, embora se trate de fatores de que o sujeito não tem inteira clareza ou consciência, e sobre os quais não tem inteiro controle. Neste âmbito, a atividade da razão possui Poder causal, só esta atividade corresponde a uma causalidade da razão na determinação do arbítrio, o que significa que a liberdade prática, enquanto propriedade do Poder causal do sujeito racional, restringe-se a esta espécie de espontaneidade, sendo portanto independente da liberdade transcendental como propriedade da atividade legislativa. É esta linha de interpretação que tentaremos defender a partir de agora.

Para defender esta linha de interpretação, discutiremos os sérios problemas em que incorre a noção incompatibilista de liberdade prática 
exposta no capítulo das Antinomias, e explícita ou implicitamente atuante em inúmeras passagens da obra kantiana. A partir de agora, portanto, nosso trabalho adquire uma visada mais abrangente, elaborando um quadro interpretativo que pretende ser fecundo para a filosofia prática kantiana como um todo.

É preciso antes de mais nada explicitar um aspecto a que implicitamente estivemos recorrendo na estruturação do argumento até aqui. Levando em conta a feição por assim dizer "regularista" ou "legalista" da teoria da ação kantiana, que tende a compreender as escolhas efetuadas em cada situação como atos que seguem certas regras gerais de escolha, ou seja, atos que exibem uma certa regularidade, pode-se afirmar que, nesta teoria, a atividade deliberativa é essencialmente uma atividade de erigir certa razão para agir em regra ou princípio (regularmente) seguido pelo arbítrio; a teoria da ação kantiana não configura a atividade deliberativa como uma atividade de escolher segundo as características particulares e variáveis de cada situação. Em conformidade com isto, pode-se dizer ainda que a regra de ação adotada na atividade deliberativa do sujeito assume a feição de princípio regularmente seguido pelas escolhas do sujeito em todo momento, ou seja, princípio segundo o qual o sujeito de fato age, e não princípio segundo o qual ele antes de tudo quer(eria) agir, ou seja, princípio segundo o qual ele quer(eria) escolher em toda situação - a diferença consiste no fato de que este último tipo de princípio por definição admite a possibilidade de que as escolhas concretas, efetuadas no calor de cada situação, muitas vezes acabem não o seguindo.

Já deve ter ficado claro que, de acordo com esta linha de análise, a distinção que estamos propondo entre a atividade deliberativa e a atividade legislativa da razão prática corresponde a uma distinção mais canônica, a qual, embora não seja extensamente discutida na Crítica da Razão Pura (aparecendo entretanto em pelo menos uma passagem, no Cânone, em B840/A812), é implicitamente operante nas análises da liberdade desta primeira Crítica, e pode ser trazida para nosso argumento. Trata-se da distinção entre, por um lado, a "máxima" como regra ou princípio segundo o qual o sujeito de fato age, e que "a razão determina em conformidade com as condições do sujeito (muitas vezes em conformidade com a ignorância ou também com as inclinações do mesmo)" (Fundamentação da Metafísica dos Costumes, nota em BA51, Ak421), e, por outro lado, as Leis práticas, que são princípios objetivos, válidos para todo ser racional, e que exprimem o modo como os sujeitos racionais (finitos) devem agir, e não o modo como eles de fato agem. Gostaríamos de sugerir que, ao 
dizer que a máxima equivale à regra prática segundo a qual o sujeito (de fato) age, Kant dá a entender que a máxima corresponde àquela regularidade de conduta que aparece aos observadores em geral - mais precisamente, corresponde a esta regularidade observável enquanto ela é considerada como regularidade de algum modo posta ou adotada pelo próprio agente como sujeito racional, e não uma regularidade que lhe teria sido simplesmente dada, independentemente de qualquer ponderação e escolha de sua parte.

Cabe então afirmar que, se a máxima pode ser caracterizada como uma "lei subjetiva" - e Allison aponta que "ao menos em algumas ocasiões Kant caracteriza as máximas como 'leis subjetivas'” (ALLISON 1990, p.86), ela está exatamente no meio do caminho entre as duas espécies de "lei objetiva" que Kant reconhece, a "lei da natureza" e a "lei da liberdade". Com efeito, enquanto pressuposto da experiência objetiva da sucessão temporal, a Lei da Natureza decerto é "a priori" quanto à forma geral da sucessão temporal objetiva, mas ela por outro lado só é "lei" no sentido de exprimir uma regularidade fenomênica, isto é, uma regularidade que simplesmente aparece aos sujeitos e é constatada por estes, uma regularidade que lhes é simplesmente dada na sensibilidade. Em contrapartida, a Lei da liberdade é objetiva no sentido de exprimir uma regularidade comportamental que deve acontecer no espaço e no tempo, ainda que de fato não aconteça, isto é, não seja empiricamente constatada. Mais precisamente, a Lei da liberdade é objetiva no sentido de exprimir uma regularidade que a razão pura "põe" a priori como regularidade que deve acontecer no espaço e no tempo, independentemente da regularidade que de fato está aparecendo e sendo empiricamente constatada.

A máxima compartilha uma característica da Lei da natureza e uma característica da Lei da liberdade - e é por isso que dissemos acima que ela está no meio do caminho entre as duas. Por um lado, ela compartilha com a Lei da natureza a característica de exprimir uma regularidade que aparece aos observadores e pode ser constatada por eles, uma regularidade cuja essência é o acontecer e aparecer - e não uma regularidade cuja essência é o dever-acontecer. Por outro lado, a regularidade comportamental expressa na máxima não pode ser tomada como uma regularidade que foi simplesmente dada ao sujeito que exibe este comportamento, independentemente de qualquer atividade de sua parte; ao contrário, ela precisa ser tomada como regularidade que este sujeito de algum modo escolheu e adotou para si mesmo. Neste sentido, a máxima compartilha com a Lei da liberdade a característica de ser espontaneamente "posta" pela razão do sujeito - ainda que não se trate aqui da razão prática pura, como ocorre na esfera da Lei da liberdade, mas de uma razão prática empiricamente condicionada, que define e "põe" sua lei de conduta em conformidade com condições subjetivas, como, por exemplo, ignorância ou inclinações 
do sujeito, o que transforma esta lei numa lei meramente subjetiva. E se a posição da Lei da liberdade é uma atividade claramente legislativa, na medida em que a Lei é neste caso uma norma que o arbítrio deve seguir, a posição da máxima enquanto lei subjetiva corresponde à atividade deliberativa da razão prática, cujo produto é o princípio que o arbítrio regularmente segue em suas escolhas e ações, e cuja manifestação externa é a regularidade comportamental empiricamente constatável.

Ora, ao afirmar que a máxima é uma regra que a razão determina em conformidade muitas vezes com as inclinações do sujeito, Kant parece abrir espaço para a interpretação de que, embora seja produto de uma atividade racional e espontânea, a máxima é produto de uma espontaneidade limitada e relativa, compatível com a influência causal das tendências naturais do sujeito, ou seja, produto de uma atividade racional determinada em última instância por fatores causais de cuja atuação o sujeito não tem inteira clareza ou consciência, e sobre os quais não tem perfeito controle. Destaque-se que esta é uma interpretação pouco usual, conflitante com a interpretação que parece contar com maior suporte textual na obra de Kant. Com efeito, na obra de Kant como um todo, parece predominar uma interpretação incompatibilista da adoção das máximas, segundo a qual a escolha e adoção das máximas seriam produto de uma atividade absolutamente espontânea da razão prática. Desse ponto de vista, dizer que a máxima é um princípio que a razão determina em conformidade muitas vezes com as inclinações do sujeito, longe de significar que tais inclinações teriam uma influência causal na atividade deliberativa de adoção das máximas, significaria, ao contrário, que a razão "por si mesma" escolhe conformar-se às inclinações naturais do sujeito.

Entretanto, mesmo que de fato conte com maior suporte textual, esta interpretação incompatibilista da atividade deliberativa padece de um grave problema: se a razão é incompatibilisticamente livre ao escolher e adotar as máximas que serão seguidas na conduta observável do agente, por que na maior parte das vezes ela escolhe máximas contrárias às leis objetivas que ela mesma reconhece e impõe como normas relativas à maneira pela qual se deve agir? No nível da espontaneidade absoluta ou incompatibilista, o Dever moral desde sempre é reconhecido como a melhor razão para agir, que de antemão sobrepuja todas as demais razões para agir possíveis. Se a escolha das máximas for compreendida como atividade dotada de espontaneidade absoluta e incompatibilista, a escolha contrária ao dever moral terá de ser compreendida como uma escolha totalmente arbitrária, indiferente àquela razão para agir que no âmbito da espontaneidade absoluta é necessariamente reconhecida como a melhor razão para agir. A nosso ver, portanto, a explicação mais plausível para a escolha contrária ao dever moral é a seguinte: a espontaneidade experimentada nesta escolha é uma espontaneidade limitada, compatível com uma determinação 
causal remota e profunda, operada por fatores de que o sujeito não tem consciência, fatores cuja atuação o sujeito não percebe com inteira clareza, e por isso mesmo não controla.

Para elaborar este problema, cabe explorar a distinção entre as atividades legislativa e deliberativa da razão prática. No campo da atividade legislativa, o caráter absoluto e incompatibilista da espontaneidade da razão vincula-se ao caráter primordialmente epistêmico da atividade legislativa. No âmbito desta atividade, a noção do dever está fundada no conhecimento de uma verdade sobre o modo racional de agir, ou seja, a "posição" da norma está baseada numa espontaneidade primordialmente epistêmica. No âmbito da atividade legislativa, o "você deve" não é oriundo de uma motivação já dada, não está fundado em uma motivação já dada, e é por isso que a validade prática dos imperativos kantianos não é primordialmente uma validade motivacional, mas uma validade epistêmica à qual se acrescenta ou pode acrescentar alguma influência motivacional. Isto fica evidente ao se considerar a forma de validade que pode ser atribuída aos imperativos hipotéticos. Como princípios objetivos, ou seja, dotados de validade para todos os agentes racionais, os imperativos hipotéticos são antes de tudo verdades, verdades sobre o modo racional de agir sob certas condições. A validade destes imperativos não é primordialmente uma validade motivacional, mas uma validade epistêmica, à qual pode se acrescentar uma influência motivacional - uma influência que de fato se concretiza quando o agente deseja alcançar o resultado expresso na antecedente da frase condicional a que o imperativo hipotético corresponde.

Também no caso do imperativo categórico a atividade legislativa da razão prática tem um caráter primordialmente epistêmico. Claro que, neste caso, o princípio goza de validade geral não apenas enquanto verdade sobre o modo (incondicionalmente) racional de agir, mas também enquanto verdade dotada de uma influência motivacional intrínseca, constituída pelo sentimento racional de respeito que neste caso acompanha a verdade reconhecida. Neste ponto da argumentação se poderia inclusive aventar a hipótese de que, no caso do imperativo categórico, se o reconhecimento desta verdade sobre o modo puramente racional de agir é obra da razão pura, a posição desta verdade como norma dotada de influência motivacional efetiva equivale ao "fazer-se" da razão pura como razão pura prática, ou seja, equivale ao "feito" no fazer-se da razão pura prática. Mas a razão pura que se faz prática equivale a uma espontaneidade epistêmica que se faz prática, o que simplesmente acentua o caráter incompatibilista inerente à espontaneidade epistêmica em Kant.

Independentemente dos possíveis desdobramentos dessa hipótese sobre o "feito" da razão pura prática, o decisivo para nosso argumento é que, no âmbito da atividade legislativa da razão prática, a imposição da norma como norma que deve ser seguida tem um claro fundamento racional, a 
saber, o conhecimento de uma verdade sobre o modo racional de agir, e este conhecimento, mesmo que se trate de uma verdade relativa ao modo racional de agir para atingir um resultado empiricamente desejado, remete a uma espontaneidade primordialmente teórica ou epistêmica. Ora, no quadro da filosofia "apriorista" e transcendental de Kant, essencialmente contrária à perspectiva naturalista da filosofia humeana, esta espontaneidade epistêmica não pode ser compreendida como expressão da mera natureza do sujeito, ou seja, não pode ser compreendida como determinada em última instância por fatores causais naturais, mas tem ao contrário de ser compreendida como espontaneidade absoluta.

O caráter absoluto e incompatibilista da espontaneidade envolvida na atividade legislativa fica ainda mais nítido no caso do imperativo categórico, onde não se trata apenas de uma espontaneidade epistêmica que contingentemente se associa a desejos empiricamente dados, mas de uma espontaneidade epistêmica que se faz prática à medida mesmo que gera um sentimento de respeito que necessariamente apresenta alguma influência motivacional para todo sujeito racional finito. Ora, este "feito" da razão pura como razão pura prática tem de ser compreendido como absolutamente independente de qualquer determinação ou influência de fatores causais pertencentes à natureza do sujeito. Mas também aqui se pode dizer que o caráter incompatibilista da espontaneidade da razão está essencialmente vinculado ao caráter primordialmente epistêmico da atividade legislativa, que não deixa de estar presente no âmbito da espontaneidade epistêmica que se faz prática, ao contrário, torna-se ainda mais nítido. E, claramente, esta ação de "fazer-se" prática da espontaneidade epistêmica é o protótipo mesmo do conceito de liberdade transcendental.

Analisemos agora a esfera da atividade deliberativa da razão prática, que no quadro interpretativo que estamos propondo equivale à atividade de escolha e adoção das máximas. A própria distinção entre imperativo e máxima, assim como a definição da máxima como princípio segundo o qual o sujeito de fato age, indicam que, neste caso, a validade da regra posta pela razão é uma validade primordialmente motivacional, o que significa que a espontaneidade implicada na posição desta regra não é uma espontaneidade primordialmente epistêmica, mas uma espontaneidade por assim dizer "decisória", implicada na decisão sobre a máxima como princípio "movedor" que será regularmente seguido pelo arbítrio. Neste caso, atribuir um caráter absoluto e incompatibilista a esta espontaneidade equivale a compreender esta decisão ou escolha como um ato arbitrário, desprovido de qualquer fundamento, causa ou motivo. Com efeito, se a atividade de escolha e adoção das máximas é incompatibilisticamente espontânea, ela é absolutamente independente de qualquer influência de motivações naturais previamente dadas ao agente, ou seja, a máxima adotada não pode ser explicada a partir de motivações naturais previamente dadas. Além disso, se a atividade de escolha e adoção das 
máximas é incompatibilisticamente espontânea, ela ocorre num contexto em que as verdades sobre o modo racional de agir são necessariamente reconhecidas como as melhores razões para agir (superiores a todas as demais razões para agir possíveis), o que significa que a escolha de uma máxima contrária a estas verdades não poderá ser compreendida como um ato baseado em fundamentos racionais. Consequentemente, se for interpretada em termos incompatibilistas, a escolha das máximas (frequentemente imorais) terá de ser compreendida como um ato absolutamente arbitrário, desprovido quer de fundamentos racionais quer de motivos naturais ou subjetivos.

No caso de um Poder de escolha incompatibilisticamente livre, não parece ser plausível a analogia com o "nadador indiferente" que Allen Wood propõe em seu artigo Kant's Compatibilism para tentar mostrar como Kant poderia deixar de comprometer-se com a incômoda ideia de uma escolha indiferente (WOOD 1984, p.81-82). Depois de afirmar que "nem toda possibilidade é um Poder", e que "algumas possibilidades, em verdade, são devidas a uma falta de Poder", ou devidas a uma falha no exercício do Poder, Wood aplica esta ideia ao nadador que tem o Poder de salvar-se nadando, caso seja lançado em águas profundas. Dizer que o nadador tem este Poder não implica negar a possibilidade de que ele venha a afogar-se - implica apenas afirmar que ele não tem o Poder de afogar-se, mas apenas a possibilidade de afogar-se. Nas palavras de Wood, "ele pode afogar-se se ele não exercer aquele Poder (de nadar) de modo efetivo, em virtude, digamos, de alguma confusão ou pânico" (IDEM, p.82). A possibilidade de afogar-se é devida a uma falha no exercício do Poder de nadar, e não a uma falta do próprio Poder. Ele continua tendo o Poder de nadar, mesmo quando não o exerce de modo efetivo.

Entretanto, a analogia não é boa quando o Poder em questão é um Poder de escolha incompatibilisticamente livre, pois um tal Poder é, por definição, um Poder que possui perfeito controle sobre seu exercício, um Poder que não tem "espaço conceitual" para a noção de falhas na execução. No caso do nadador, o Poder de salvar-se nadando é distinto do Poder de escolher o que fazer ao ser lançado em águas profundas. E, embora a falha no exercício do Poder de salvar-se nadando possa ser atribuída a um certo exercício do Poder de escolher o que fazer ao ser lançado em águas profundas, um exercício igualmente falho, isto só faz sentido caso o exercício deste último Poder, o de escolha, seja compreendido em termos compatibilistas, como um exercício determinado em última instância por fatores causais dados ao agente, de cuja atuação ele não tem inteira consciência e sobre os quais não tem perfeito controle - fatores cuja atuação pode ser descrita em termos, por exemplo, de "confusão mental" ou "pânico".

Se o Poder de escolher o que fazer ao ser lançado em águas profundas for compreendido em termos incompatibilistas, como um Poder cujo 
exercício, longe de ser determinado por uma causalidade natural remota e profunda, dependeria apenas de si mesmo, - ou seja, se o Poder de escolha for compreendido como um poder sobre cujo exercício o agente tem perfeito controle, o nadador que tem o Poder de salvar-se nadando só se afogará ao ser lançado em águas profundas caso (espontaneamente) escolha afogar-se - seria então, justamente, uma escolha arbitrária, absurdamente indiferente. $\mathrm{O}$ nadador incompatibilisticamente livre não apenas sabe o que "deve fazer" para salvar-se ao ser lançado em águas profundas, como tem o Poder para efetivamente salvar-se nadando; admitindo-se que suas ações sejam expressão de suas escolhas ao ser lançado em águas profundas, e admitindo-se que estas escolhas não possam ser atribuídas a fatores causais dos quais ele não tem inteira consciência e sobre os quais não tem controle, ele só não escolhe fazer aquilo que sabe que deve fazer (para salvar-se) e tem o Poder para fazer por consciente e espontaneamente escolher o contrário, ou seja, por "livremente" (arbitrariamente, indiferentemente) escolher não fazer aquilo que sabe que deve fazer e tem o Poder para fazer.

Um problema semelhante pode ser detectado no conceito de "caráter inteligível", que é essencial à concepção incompatibilista da liberdade prática exposta no capítulo das antinomias. Em B567/A539, Kant introduz o conceito de caráter através da seguinte afirmação: “Toda causa eficiente tem que possuir um caráter, isto é, uma lei da sua causalidade, sem a qual ela de modo algum seria uma causa". A definição de "caráter" não poderia ser mais clara: caráter é a lei da causalidade de uma causa eficiente, ou seja, a lei seguida pelo Poder e pela atividade causal de uma causa eficiente. Consequentemente, se o arbítrio humano é causa eficiente de ações como eventos que acontecem no espaço e tempo, o arbítrio humano tem um "caráter", ou seja, uma lei da sua atividade causal.

Logo depois da introdução do conceito de caráter, ainda em B567/A539, Kant afirma que nós teríamos em um "sujeito do mundo dos sentidos" primeiramente um "caráter empírico", isto é, "um caráter pelo qual suas [do sujeito] ações, enquanto fenômenos, se interconectariam completamente com outros fenômenos segundo leis constantes da natureza, e poderiam ser derivadas destes, enquanto eles são suas condições". Mas teríamos em segundo lugar um "caráter inteligível", "pelo qual aquele sujeito é a causa daquelas ações enquanto fenômenos, ele mesmo [o caráter inteligível A.S.B.], no entanto, não se subordinando a quaisquer condições da sensibilidade e não sendo, pois, um fenômeno". E em B574/A546 Kant deixa claro que o caráter inteligível, enquanto "causa transcendental" do caráter empírico, deve ser deixado de lado como algo desconhecido, "exceto na medida em que nos pode ser indicado (angegeben) pelo caráter empírico, enquanto seu [do caráter inteligível] sinal sensível" - ou, parafraseando a mesma afirmação com os termos de uma passagem anterior: embora 
seja cognitivamente inacessível, o caráter inteligível pode ser indicado pelo caráter empírico enquanto "fenômeno (Erscheinung) do inteligível" (B569/A541).

O conceito de caráter empírico padece de certa ambiguidade, que tem a ver com uma ambiguidade no conceito de causa, ou na noção de "eficácia causal". Como explica Allen Wood no artigo já mencionado, podem-se notar duas tendências na compreensão da noção de eficácia causal. De acordo com uma primeira tendência, que Wood chama de "aristotélica", a eficácia causal é uma propriedade de substâncias ou agentes, que não pode ser analisada em termos de noções mais simples (WOOD 1984, p.88). De acordo com a outra tendência, que Wood chama de "humeana", a eficácia causal é uma propriedade de eventos e pode ser analisada em termos de uma relação de "conjunção constante" entre eventos semelhantes. Para Wood, no que diz respeito à causalidade da natureza, Kant opta pela tendência "humeana", embora queira preservar a noção aristotélica em relação à causalidade inteligível dos agentes livres.

No que diz respeito ao caráter empírico do arbítrio humano, entretanto, não nos parece tão claro que Kant opte inequivocamente pela "tendência humeana". Em algumas passagens do capítulo das antinomias - por exemplo, uma famosa passagem em B577/A549 em que Kant afirma que o caráter empírico "tem de ser extraído dos fenômenos como efeito e da regra dos fenômenos que a experiência fornece", passagem que pode ser interpretada no sentido de que a regra ou regularidade meramente fenomênica é efeito do caráter empírico, que presumidamente pertenceria a uma "substância" dotada de eficácia causal, - em algumas passagens parece haver algum espaço para a "tendência aristotélica" de compreensão do caráter empírico, desde que a substância dotada de eficácia causal seja tomada como substância puramente natural, ou seja, substância cuja atividade causal é mecanicamente determinada por causas estritamente naturais, como impulsos da sensibilidade.

$\mathrm{Na}$ verdade, a ambiguidade apontada por Wood claramente se acentua quando a "eficácia causal" se refere ao arbítrio humano. Com efeito, quando ela se refere a uma causalidade que naturalmente pode ser tratada apenas do ponto de vista do observador externo, a ambiguidade só diz respeito ao modo como este observador compreende a eficácia causal que ele vê à sua frente - ou ele a compreende como propriedade redutível à conjunção constante de "aparições" semelhantes, ou então como propriedade de uma substância, mas uma substância cuja essência é funcionar segundo leis constantes e invariáveis. Entretanto, quando a eficácia causal se refere ao arbítrio humano, a questão se complica, pois não é tão natural assim tratar a causalidade do arbítrio apenas do ponto de vista do observador externo. Neste caso, a ambiguidade que se apresenta no ponto de vista do observador é acentuada por uma tensão entre este ponto de vista - do 
observador externo - e o ponto de vista do sujeito que não pode deixar de se ver como a "coisa" que "tem" um arbítrio, uma vontade, um Poder causal. Neste caso, em outras palavras, a "tendência aristotélica" se desdobra em duas subtendências - na verdade ela se desdobra em três subtendências. Em primeiro lugar, a tendência a encarar esta coisa que tem um arbítrio como uma substância puramente natural, ou seja, uma substância cuja atividade causal é mecanicamente determinada por fatores causais previamente dados no tempo; em segundo lugar, a tendência a encarar a coisa que tem um arbítrio como um sujeito racional, ou seja, um sujeito cuja atividade causal é determinada por uma atividade deliberativa em alguma medida espontânea. Só que esta última tendência imediatamente se divide em duas, de acordo com a compreensão que se adota desta "atividade deliberativa em alguma medida espontânea".

Numa primeira subdivisão desta última tendência, a causalidade do sujeito racional é compreendida como uma causalidade determinada por uma atividade deliberativa "relativamente espontânea", ou seja, uma atividade deliberativa compatível com a influência em última instância determinante de fatores causais remotos e profundos, de cuja atuação o sujeito não tem inteira consciência e sobre os quais não tem inteiro controle. (Embora não haja espaço para discutir esta questão neste momento, esta alternativa, que é a alternativa que estou procurando defender, envolve uma compreensão do sujeito racional finito como substância em certo sentido natural, mas não no sentido de mecanicamente determinada por fatores causais alheios ao fim da plena liberdade, e sim no sentido de teleologicamente estruturada, ou seja, no sentido de uma substância cuja causalidade remota e profunda está orientada para um fim, o da plena liberdade, cuja realização exige a superação de determinados obstáculos por intermédio da esperança e fé na realização deste fim. Na última seção voltarei brevemente a esta concepção, a meu ver a única capaz de evitar os sérios problemas envolvidos numa interpretação incompatibilista da liberdade prática). Por fim, pode-se compreender a causalidade do sujeito racional como causalidade determinada por uma atividade deliberativa "absolutamente espontânea", ou seja, uma atividade na qual a razão desde sempre atua apenas "por si mesma", sem qualquer influência de fatores causais previamente dados no tempo.

Emergem assim quatro possibilidades de compreensão da eficácia causal do arbítrio humano. Em primeiro lugar, ela pode ser compreendida como uma propriedade fundamentalmente fenomênica, redutível à regularidade com que ações semelhantes aparecem em conjunção com circunstâncias semelhantes. Em segundo lugar, ela pode ser compreendida como propriedade de uma substância estritamente natural, isto é, mecanicamente estruturada e determinada. Em terceiro lugar, a eficácia causal do arbítrio humano pode ser compreendida como propriedade de um sujeito racional relativamente (compatibilisticamente) espontâneo. (Neste caso, como dito 
acima, a espontaneidade deliberativa experimentada pelo sujeito racional é compatível com a causalidade profunda de uma natureza teleologicamente estruturada). Em quarto lugar, por fim, a eficácia causal do arbítrio humano pode ser compreendida como propriedade de um sujeito racional absolutamente (incompatibilisticamente) espontâneo.

Ora, ainda que se admita que o "caráter empírico" apresentado no capítulo das antinomias padeça de uma ambiguidade ou tensão, a própria oposição ao caráter inteligível torna inegável que esta ambiguidade ocorre apenas entre as duas primeiras possibilidades acima apresentadas. Em outras palavras, a ambiguidade no conceito de caráter empírico é uma ambiguidade entre uma compreensão meramente fenomênica da eficácia causal do arbítrio humano e uma compreensão "substancialista-naturalista-mecanicista" desta eficácia causal, segundo a qual ela é propriedade de uma substância estritamente natural, cuja causalidade é puramente mecânica, alheia ao fim da plena liberdade.

E é igualmente inegável que, ao afirmar que o caráter empírico é "fenômeno" do caráter inteligível, ou que o caráter inteligível é a "causa transcendental" do caráter empírico, - é inegável que, ao fazer estas afirmações, correlatas da afirmação de que a liberdade prática depende da transcendental, Kant está estabelecendo uma correspondência entre o caráter inteligível e a compreensão incompatibilista da eficácia causal do sujeito racional, segundo a qual esta eficácia causal deve ser compreendida como propriedade de um sujeito cuja causalidade é determinada por uma atividade deliberativa absoluta e incompatibilisticamente espontânea. Desse ponto de vista, o caráter empírico seria efeito de uma atividade causal puramente inteligível, incompatibilisticamente livre - e este efeito poderia então ser compreendido quer como regularidade estritamente fenomênica, quer como regularidade das ações do "sujeito fenomênico" enquanto substância puramente natural, cujas ações são regulares na medida em que são mecanicamente determinadas e temporalmente encadeadas segundo leis constantes. Esta atividade absolutamente livre, que se determina a partir apenas de si mesma, ou por si mesma, corresponderia então ao caráter inteligível do sujeito racional.

Ora, o texto das Antinomias sugere fortemente a ideia de que esta atividade absolutamente livre deva ser identificada a uma atividade do sujeito racional de escolher qual será seu "caráter empírico". Se no plano dos fenômenos as ações do sujeito fenomênico seguem o caráter empírico deste sujeito, ou seja, exibem a rigorosa regularidade própria dos eventos temporalmente encadeados, este caráter empírico, ou esta regularidade, são por outro lado "postos" ou "escolhidos" pelo sujeito noumênico e inteligível, numa escolha que, apesar de "fora do tempo", pode exibir efeitos variáveis no tempo, ou seja, pode acarretar variações temporais no caráter empírico do sujeito fenomênico. 
Esta compreensão incompatibilista do caráter inteligível e da sua relação com o caráter empírico é muito bem exposta por Allen Wood, numa passagem que, apesar de referida a um trecho da Crítica da Razão Prática, aplica-se perfeitamente às análises de Kant no capítulo das Antinomias - trata-se de um trecho da Elucidação Crítica da Analítica da Razão Pura Prática em que o próprio Kant faz referência à Crítica da Razão Pura. Embora a citação seja longa, vale a pena citá-la por inteiro (WOOD 1984, p.91)

A teoria de Kant parece ser a seguinte. Os eventos no tempo seguem uma ordem necessária, determinada por suas causas naturais. Uma escolha particular e atemporal realizada por meu caráter inteligível afeta o mundo natural, selecionando um certo subconjunto de mundos possíveis, a saber, aqueles que incluem uma certa história moral para meu caráter empírico, e determinando que o mundo real será extraído deste subconjunto de possibilidades. Para cada escolha deste tipo há uma quase infinita variedade de modos pelos quais eu poderia ter escolhido diferentemente, uma infinita variedade de possíveis eus empíricos e histórias morais pessoais que eu poderia ter realizado. De cada uma das minhas más ações é verdade que eu deixaria de tê-la praticado se eu tivesse feito uma escolha atemporal diferente. Portanto, está em meu poder deixar de praticar qualquer má ação, embora no mundo real ela inevitavelmente se siga daquilo que a precedeu no tempo.

Wood discute longamente os problemas implicados por esta noção de uma escolha atemporal, a qual, se por um lado define "atemporalmente" a regularidade fenomênica própria do meu caráter empírico, tornando necessárias cada uma das minhas ações como sujeito fenomênico, por outro lado, para evitar o espectro de "fatalismo", deve ser vista como tendo "influência imediata sobre cada um dos nossos atos", devendo ser considerada "simultânea com cada ato, à medida que vai ocorrendo na ordem temporal" (WOOD 1984, p.96). Entretanto, embora a densidade destes problemas possa ser considerada uma desvantagem para a interpretação incompatibilista da atividade de escolha como atividade essencial da liberdade humana, não preciso discuti-los aqui, pois a razão decisiva contra esta interpretação parece-me residir em outro ponto, ao qual Wood não dá atenção, a saber, o caráter em última instância arbitrário da escolha - que pode ser descrita como escolha quer do caráter empírico quer das máximas como regras constitutivas da regularidade comportamental observável. Por que a razão que produz um certo caráter empírico escolhendo a regularidade comportamental constitutiva deste caráter (ou escolhendo a máxima enquanto regularidade observável), - por que esta razão se desvia da Lei da liberdade que ela mesma legisla ou põe para sua causalidade? Por que o sujeito racional incompatibilisticamente livre se desvia daquela norma que, no âmbito da espontaneidade absoluta, é necessariamente reconhecida como a melhor razão para agir?

Em estreita conexão com este problema, pode-se apontar outro. Se o par conceitual caráter empírico / caráter inteligível é essencial à interpreta- 
ção incompatibilista da liberdade prática exposta nas Antinomias, esta interpretação é gravemente debilitada por um problema grave no próprio conceito de caráter inteligível. Kant define "caráter" como "a lei da causalidade de uma causa eficiente, sem a qual ela de modo algum seria uma causa". Ora, a "lei da causalidade de uma causa eficiente" só pode ser interpretada como a lei efetivamente seguida pela atividade causal de uma causa eficiente, ou a lei pela qual ela efetivamente produz seus efeitos. O "caráter empírico" claramente corresponde a esta definição: ele é a lei seguida pela atividade causal do sujeito fenomênico como substância estritamente natural. Entretanto, qual seria a "lei da causalidade" da razão como causa eficiente puramente inteligível, causa que produz como efeito os fenômenos e a regularidade fenomênica constitutivos do caráter empírico? Não pode ser a Lei da liberdade, pois a atividade causal que produz o caráter empírico não segue esta lei, como fica demonstrado pelo fato de que o caráter empírico quase sempre se desvia da Lei da liberdade. Mas tampouco a Lei da natureza pode ser a lei da causalidade da razão como causa eficiente puramente inteligível, pois a Lei da natureza só pode existir e se aplicar no plano dos fenômenos temporalmente encadeados. Percebe-se então que o "caráter inteligível" não pode equivaler a uma "Lei da causalidade de uma causa eficiente", não pode equivaler a um "caráter" tal como definido por Kant no capítulo das Antinomias, mas tem de corresponder a um ato de escolha arbitrário, indiferente a todas as leis...

Vejamos agora de que modo a interpretação compatibilista da liberdade prática como propriedade da atividade deliberativa, assim como a distinção entre espontaneidade legislativa e espontaneidade deliberativa na qual tal interpretação se baseia, permitiriam encaminhar uma solução destes problemas conciliável com o espírito geral da filosofia prática e moral kantiana. Limitar-nos-emos a uma exposição esquemática do quadro geral que seria possibilitado por esta interpretação, o qual precisará ser cotejado com as outras obras de Kant sobre filosofia prática, incluindo as análises sobre as relações entre reino da natureza e reino da liberdade efetuadas na Crítica do Juízo.

No quadro geral que em princípio seria possibilitado pela interpretação que estamos propondo, a atividade legislativa da razão prática é uma atividade puramente inteligível, absolutamente independente da causalidade que atua no tempo; trata-se então de uma atividade transcendentalmente livre, dotada de uma espontaneidade absoluta. Esta atividade tem um caráter primordialmente epistêmico, seus produtos são antes de tudo verdades sobre o modo racional de agir; mais precisamente, seus produtos são estas 
verdades enquanto verdades postas para a atividade deliberativa, para serem ponderadas na atividade deliberativa. Os produtos da atividade legislativa dividem-se em duas grandes espécies de verdade. Há em primeiro lugar verdades sobre o modo racional de agir para atingir determinados resultados, que são postas para a atividade deliberativa como imperativos hipotéticos, sob a seguinte forma geral: se você deseja atingir o resultado $X$, você deve fazer $Y$.

No âmbito da atividade deliberativa, os imperativos hipotéticos só adquirem influência motivacional à medida que são associados a desejos dados na sensibilidade, a saber, desejos de alcançar o resultado X. Ao adquirirem influência motivacional no âmbito da atividade deliberativa, os imperativos hipotéticos se tornam membros do conjunto das razões para agir que são ponderadas e ajuizadas pela atividade deliberativa como atividade dotada de uma espontaneidade relativa ou limitada. Isto significa que eles adquirem a possibilidade de serem espontaneamente (mas com uma espontaneidade limitada e relativa) escolhidos e adotados como regra de conduta que será efetivamente seguida pelo arbítrio. Dizer que se trata de uma espontaneidade limitada é dizer que a realização ou não desta possibilidade não depende apenas da atividade deliberativa experimentada como espontânea, mas depende também de influências causais remotas e profundas, das quais o sujeito não tem inteira consciência, e sobre cuja atuação não tem controle.

O principal produto da atividade legislativa não é, porém, o imperativo hipotético, mas o imperativo categórico. $\mathrm{O}$ imperativo categórico é uma verdade sobre o modo incondicionalmente racional de agir. A posição do imperativo categórico para a atividade deliberativa equivale a um "fazer-se prática" da espontaneidade primordialmente epistêmica da razão pura; isto significa que a verdade expressa no imperativo é posta para a atividade deliberativa com uma influência motivacional intrínseca, absolutamente independente de desejos dados na sensibilidade. Em outras palavras, significa que, ao contrário do imperativo hipotético, o imperativo categórico não precisa associar-se a nenhum desejo sensível para tornar-se membro do conjunto das razões para agir que são ponderadas e ajuizadas pela atividade deliberativa como atividade dotada de uma espontaneidade limitada. Por outro lado, do mesmo modo que ocorre com o imperativo hipotético, ao tornar-se membro deste conjunto de razões para agir, o imperativo categórico adquire apenas a possibilidade de ser espontaneamente (mas com uma espontaneidade limitada e relativa) escolhido e adotado como regra de conduta que será efetivamente seguida pelo arbítrio. Do mesmo modo que ocorre com o imperativo hipotético, dizer que se trata de uma espontaneidade limitada é dizer que a realização ou não desta possibilidade não depende apenas da atividade deliberativa experimentada como espontânea, mas depende também de influências causais remotas e profundas, das quais o sujeito não tem inteira consciência, e sobre cuja atuação não tem controle. 
No caso do imperativo categórico, portanto, a posição do "você deve" é a posição de uma possibilidade, uma possibilidade que, como fim ou finalidade, é constitutiva da liberdade prática do sujeito racional finito, ou constitutiva da natureza deste sujeito, pensada como natureza dotada de uma espontaneidade orientada para um fim, o da plena realização da liberdade humana. Trata-se da possibilidade de que o imperativo categórico (a Lei da Razão Pura) seja escolhido e adotado como regra de conduta ("máxima") que será efetivamente seguida pelo arbítrio, o que equivaleria, justamente, à realização plena e perfeita da liberdade humana. Mas a liberdade (espontaneidade) prática do sujeito racional não consiste no Poder de decidir "por si mesmo" se esta possibilidade (ou este fim) se realiza ou não. A realização ou não desta possibilidade (deste fim) depende de influências causais remotas e profundas, das quais o sujeito racional não tem perfeita consciência e sobre cuja atuação não tem controle.

Estas influências causais podem e devem ser pensadas em termos de uma causalidade teleologicamente estruturada, isto é, uma causalidade que está orientada para o fim da plena liberdade, embora a realização do mesmo exija a superação de determinados obstáculos por intermédio da esperança e fé na realização deste fim ou possibilidade. Isto significa duas coisas. Em primeiro lugar, tudo que o sujeito racional pode fazer em relação a esta possibilidade ou fim é ter esperança e fé na realização do mesmo. Em segundo lugar, mas muito mais importante: ter esperança e fé na realização desta possibilidade ou fim, e deixar que elas nutram o esforço esperançoso pelo qual, talvez, a esperança acabe por se auto-realizar, - isto é o dever supremo do sujeito racional finito.

\section{Referências Bibliográficas}

ALLISON, Henry. Kant's Theory of Freedom. Cambridge: Cambridge University Press, 1990.

ALMEIDA, Guido Antônio. "Liberdade e Moralidade segundo Kant". Analytica, v. 2, n.1, p. 175-202. 1997.

ALMEIDA, Guido Antônio de. Notas. São Paulo: Discurso Editorial - Barcarolla, 2009.

GUYER, Paul. Kant. Londres: Routledge, 2006

KANT, Immanuel. Werke in zehn Bänden. Hrsg. von Wilhelm Weischedel. Darmstadt: Wissenschaftliche Buchgesellschaft.

. Crítica da Razão Pura. Tradução de Valerio Rohden e Udo Moosburger. São Paulo: Editora Nova Cultural, 1999. 
Fundamentação da Metafísica dos Costumes. Tradução, Introdução e Notas de Guido Antônio de Almeida. São Paulo: Discurso Editorial - Barcarolla, 2009.

KORSGAARD, Christine. Creating the Kingdom of Ends. Cambridge: Cambridge University Press, 1996.

O'NEILL, Onora. Constructions of Reason: Explorations of Kant's Practical Philosophy. Cambridge: Cambridge University Press, 1989.

WOOD, Allen. "Kant's Compatibilism". In Allen Wood (ed.) Self and Nature in Kant's Philosophy, p. 73-101. Ithaca: Cornell University Press, 1984.

Endereço do Autor:

Rua Desembargador Burle, n.41, Ap. 202.

Humaitá

22271-060 Rio de Janeiro - RJ

antoniofsbraga@uol.com.br 